Research article

\title{
Torrefaction influence on combustion kinetics of Malaysian oil palm wastes
}

\author{
Blanca Castells ${ }^{a, b, *}$, Isabel Amez ${ }^{a}$, Ljiljana Medic ${ }^{\text {a,b }}$, Javier García-Torrent ${ }^{\text {a,b }}$ \\ ${ }^{a}$ Department of Energy and Fuels, E.T.S. Ingenieros de Minas y Energía, Universidad Politécnica de Madrid, Rios Rosas 21, 28003 Madrid, Spain \\ ${ }^{\mathrm{b}}$ Laboratorio Oficial JM Madariaga (LOM), Universidad Politécnica de Madrid, Madrid, Spain
}

\section{A R T I C L E I N F O}

\section{Keywords:}

Thermal degradation kinetics

Oil palm wastes

Freeman-Carroll

Coats-Redfern

Lignocellulosic biomass

Fraser-Suzuki deconvolution

\begin{abstract}
A B S T R A C T
The use of renewable energy has increased in the last decades including the consumption of biofuels, so the research focused on improving these energetic vectors has increased too, developing techniques that enhance energetic properties of these fuels. In this context, torrefaction is a thermal pre-treatment that diminishes the main disadvantages present in biomass such as hygroscopicity, low calorific value per unit mass and high susceptibility to self-ignition. In this study raw and torrefied palm oil wastes samples are tested using thermogravimetric analysis (TGA) in order to study the influence of torrefaction on combustion kinetic parameters using Coats-Redfern and Freeman-Carroll methods, showing that torrefaction increases activation energy as it enhances thermal stability of the samples. The composition of the samples is also estimated using TGA through Fraser-Suzuki deconvolution showing the changes of lignin, cellulose, and hemicellulose due to torrefaction process.
\end{abstract}

\section{Introduction}

Because of global warming, the energy system has been changing significantly over the last decade increasing enormously the use of renewable fuels and diminishing fossil fuels dependence [1]. This new scenario provides a chance for renewable energy resources such as wind, solar, geothermal, but also for biofuels that could have an important role in the energy system of the next years [2]. More than twenty years ago, the use of biomass instead of solid fossil fuels was proposed [3] and nowadays is becoming a reality [1]. Biomass can be produced from different wastes as agricultural, forestry, sludge, etc., and presents important advantages as its combustion does not contribute to the greenhouse effect, allows the transition to a low carbon economy, has low content of most trace elements, etc. [4].

In this context, Malaysia has a great potential generating biomass as a renewable energy source because of its oil palm crops. According to Malaysian Palm Oil Board (MPOB) statistics [5], Malaysia is the second largest producer (after Indonesia [6]) of palm oil, which means that palm oil production is a key factor for Malaysian economy but also, generates a huge amount of palm wastes. Only $10 \%$ of the total palm matter is used for oil products, which means that the remaining $90 \%$ constitutes palm wastes that can be used as biomass [7]. But in order to do that, some problems need to be solved as its low calorific value, its difficult transportation and its hygroscopicity [8]. Those problems are not limited to palm oil wastes but are present in most of the lignocellulosic biomass. Thus, treatment must be carried out to improve the efficiency of biomass and lead it to a use increase.

Within this framework, pre-treating biomass using torrefaction process is a possible solution for the main biomass disadvantages as it decreases oxygen content and increases bulk density and calorific value [9]. Because of that, in the past years, the research on palm oil wastes torrefaction has increased [7,10-13]. Dry torrefaction is a mild pyrolysis carried out in anoxic atmospheres under atmospheric pressure and temperature range from $200{ }^{\circ} \mathrm{C}$ to $300{ }^{\circ} \mathrm{C}$ [14]. Previous works showed that torrefied biomass improves combustion and pyrolysis efficiency $[15,16]$ so, in order to properly develop combustion, it is important to know the mechanisms that take place during the process and the kinetic parameters $[17,18]$ that define the reactions. Thermogravimetric Analysis (TGA) has proved to be a good technique widely used to define kinetic reactions for lignocellulosic biomass [19-23], as it records the weight loss with high precision when carrying out oxidation at low heating rates. The kinetic mechanisms can be approached from TGA using two different types of methods: model fitting methods and model free methods. Model fitting methods fit different models to the obtained data allowing the calculation of the apparent activation energy (Ea) and preexponential factor (A). Coats-Redfern [24] and Freeman-Carroll [25] are both model fitting methods. On the other hand, model free methods do not make any model assumptions and determine the activation

\footnotetext{
* Corresponding author at: C/Alenza, 4, Madrid 28003, Spain.

E-mail address: b.castells@upm.es (B. Castells).
} 
energy as a function of the conversion factor or temperature however, model free methods are more complex and the calculation of preexponential factor requires the knowledge of reaction mechanism, so assumptions need to be done [26]. Model free methods includes Friedman [27], Kissinger [28], Kissinger-Akahira-Sonuse (KAS) [29], FlynnWall-Ozawa (FWO) [30,31], Distributed Activation Energy Model (DAEM) [32,33], etc. In the last years, the focus on the kinetics of torrefaction process has increased [34-38], in order to optimize and improve efficiency of the process.

In the present study model fitting methods are applied in order to define kinetic parameters of combustion of three different samples from oil palm wastes before and after torrefaction applying TG analysis.

\section{Materials and methods}

\subsection{Materials}

The samples studied in the present work come from palm oil wastes (Elaes Oleifera) from Johor (Malaysia) palm fields. The samples come from different parts of the tree: empty fruit bunches (EFB), palm kernel shell (PKS) and palm mesocarp fibre (PFM). The samples were drytorrefied at two different temperatures: $250{ }^{\circ} \mathrm{C}$ (T1) and $300{ }^{\circ} \mathrm{C}(\mathrm{T} 2)$. Fig. 1 shows the samples before and after the process and notices the colour change due to torrefaction [7].

\subsection{Biomass characterization and torrefaction}

Proximate analysis was performed, according to standard procedures, in all samples so values for moisture, ash and volatile content were

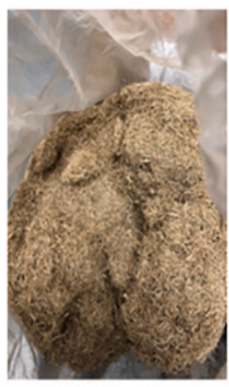

EFB

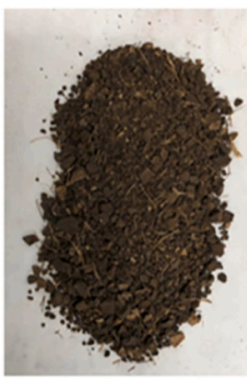

PKS

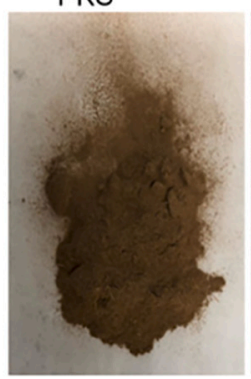

PMF

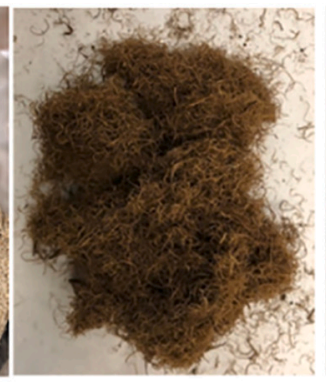

EFB T1

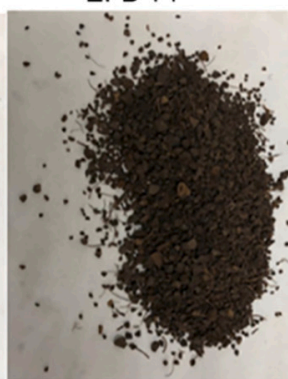

PKS T1

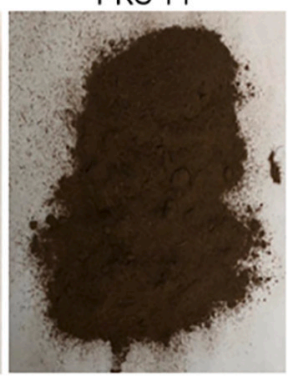

PMF T1

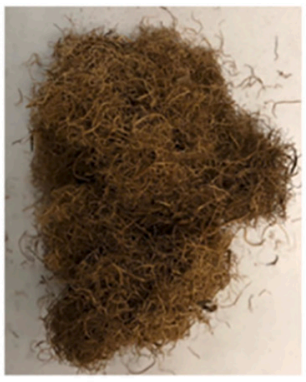

EFB T2

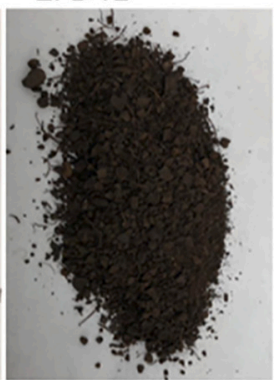

PKS T2

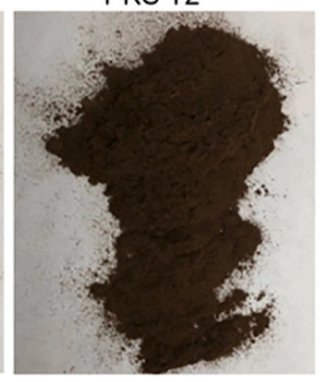

PMF T2
Fig. 1. Palm oil wastes samples (feedstock and torrefied) obtained, thus fixed carbon was calculated. Moisture content was obtained using Mettler Toledo HB43 halogen analyser in order to obtain more precise values. Moisture content is an important characteristic of solid biofuels as it affects the calorific value of the fuel, as fuels with high moisture content will require more energy to evaporate the water present in the fuel. On the other hand, the volatile content should be high for good fuels, as it indicates the ignition easiness, however, it might be counterproductive for torrefaction as it might produce tar and smokes [5]. Ashes normally increase after torrefaction, as they represent the non-combustible matter in the sample. Subtracting ashes, moisture and volatile matter, fixed carbon content is obtained. High fixed carbon content will contribute to char formation [39].

As it has been said, dry torrefaction is a mild pyrolysis process carried out under certain conditions of temperature and time. In the present work, torrefaction was carried out, after $24 \mathrm{~h}$ drying at $105{ }^{\circ} \mathrm{C}$, at two different temperatures: $250{ }^{\circ} \mathrm{C}$ and $300{ }^{\circ} \mathrm{C}$ (before and after holocellulose decomposition), during a residence time of $30 \mathrm{~min}$ in both cases as some previous studies showed that temperature has higher impact than time, especially regarding palm oil wastes $[12,40]$. Torrefaction was carried out in an anoxic atmosphere generated by adding an inert gas (nitrogen) until the oxygen inside the reactor was beneath $0.1 \%$ measured using an oxygen analyser. Time and torrefaction temperatures have been established according to literature [12,38,41].

All the samples are lignocellulosic biomasses, which means that they are composed of lignin, hemicellulose, and cellulose. According to Sukiran et al. [5], the thermal degradation of hemicellulose takes place between $200{ }^{\circ} \mathrm{C}$ and $320{ }^{\circ} \mathrm{C}$ followed by cellulose decomposition between $300^{\circ} \mathrm{C}$ and $360^{\circ} \mathrm{C}$; while lignin decomposition is a slower process due to its complex chemical composition that occurs between $200{ }^{\circ} \mathrm{C}$ and $800{ }^{\circ} \mathrm{C}$. Considering these degradation temperatures, after the torrefaction processes applied in this study, hemicellulose should decrease from feedstock biomass to torrefied biomass, even in a more intense way when applying torrefaction at $300^{\circ} \mathrm{C}$.

During torrefaction, three main reactions take place: decomposition, devolatilization and depolymerization; that modifies the chemical structure of the biomass increasing lignin content while decreasing hemicellulose and cellulose content [9].

\subsection{Thermogravimetric analysis}

Thermogravimetric Analysis (TGA) was performed using a Mettler Toledo TG-DSC T50 apparatus. The samples were heated from $30{ }^{\circ} \mathrm{C}$ to $800{ }^{\circ} \mathrm{C}$, and the heating rate was set up at $5 \mathrm{~K} / \mathrm{min}$ as it reduces the thermal lag [42] and produces slow oxidation so the stages are well differentiated and the kinetic analysis can be carried out. The samples were ground and sieved in order to obtain particle size lower than $1 \mathrm{~mm}$ and were inserted in the oven inside alumina crucibles. The analysis result is a curve that provides information regarding kinetics, composition, and thermal behaviour, as the onset temperature, which is the temperature at which the reaction accelerates.

\subsection{Kinetic models}

As it has been said before, in this work two different kinetic model fitting methods are considered: Coats-Redfern (CR) and Freeman-Carroll (FC). Both methods present a different approach to the general rate equation used in non-isothermal kinetics, which can be written as:

$\frac{d \alpha}{d t}=k(T) \cdot f(\alpha)$

Where $t$ is time, $T$ temperature, $k(T)$ is the constant rate, $f(\alpha)$ is the reaction model depending on the reaction mechanism and $\alpha$ is the conversion factor defined as $\alpha=\left(m_{0}-m_{t}\right) /\left(m_{f}-m_{0}\right)$, where $m_{0}$ is the initial mass before the reaction, $m_{f}$ is the final mass after the reaction and $m_{t}$ is the mass at time $t$. The constant rate is defined according to Arrhenius law, so the equation can be rewritten as: 
$\frac{d \alpha}{d t}=A \cdot e^{\frac{-E a}{K T}} \cdot f(\alpha)$

Where $E a$ is the apparent activation energy, $R$ is the ideal gas constant and $A$ is the preexponential factor. And considering that TGA is a non-isothermal method but the heating rate is constant, the equation can be modified considering the heating rate $\beta$ as $d T=\beta \cdot d t$.

$\frac{d \alpha}{d T}=\frac{A}{\beta} \cdot e^{\frac{-E \alpha}{K T}} \cdot f(\alpha)$

Regarding the reaction model $f(\alpha)$, the most commonly used model is the power-law kinetics or $n$-order kinetics reaction proportional to the concentration of nondegraded material and it is defined as:

$f(\alpha)=(1-\alpha)^{n}$

Where $n$ is the reaction order. However, many authors consider other reaction models $[43,44]$ such as phase boundary controlled reaction, diffusion, random nucleation, etc. Table 1 shows the models used in this work besides the n-order kinetics mentioned above.

The main difference between CR and FC methods lies in the approach of eq. 3, as CR is an integral method (the weight loss versus temperature data is used directly) and FC is a differential method (it uses the rate of weight loss versus temperature). Rearranging eq. 3 and applying integrals, the following expression is obtained, which is the basis of the Coats-Redfern method:

$\int \frac{1}{f(\alpha)} d \alpha=\frac{A}{\beta} \int e^{-\frac{E a}{R T}} d T$

If the first term is called $g(\alpha)$ and the second term is approximated as it does not have an exact integral, Eq. (5) becomes:

$g(\alpha)=\frac{A R T^{2}}{\beta E a}\left(1-\frac{2 R T}{E a}\right) e^{-\frac{E a}{R T}}$

Taking logarithms at both sides, Eq. (5) becomes:

$\ln \frac{g(\alpha)}{T^{2}}=\ln \left[\frac{A R}{\beta E a}\left(1-\frac{2 R T}{E a}\right)\right]-\frac{E a}{R T}$

If the first term of Eq. (7) is plotted versus $1 / T$, a line is obtained whose slope corresponds to $-E a / R$ so the apparent activation energy is obtained. It is also possible to calculate the preexponential factor using the $y$-intercept of the line. If the model reaction $f(\alpha)$ considered is the one expressed in Eq. (4), the first term of Eq. (7) has two values depending on the order reaction $n$ :

for $n \neq 1 \ln \frac{g(\alpha)}{T^{2}}=\ln \left[\frac{1-(1-\alpha)^{1-n}}{T^{2}(1-n)}\right]$

for $n=1 \ln \frac{g(\alpha)}{T^{2}}=\ln \left[\frac{-\ln (1-\alpha)}{T^{2}}\right]$

As it has been mentioned, Coats-Redfern is an integral method while Freeman-Carroll is a differential method which considers a degradation reaction whose order is unknown but can be obtained at the same time as activation energy. The main advantage of the method is that there is no presumption of the reaction order (activation energy and reaction

Table 1

Most common used kinetic models.

\begin{tabular}{ll}
\hline Kinetic Model & $\mathrm{f}(\alpha)$ \\
\hline Phase boundary-controlled reaction (contracting area) (R2) & $2(1-\alpha)^{1 / 2}$ \\
Phase boundary-controlled reaction (contracting volume) (R3) & $3(1-\alpha)^{2 / 3}$ \\
2D diffusion (D2) & $\frac{1}{-\ln (1-\alpha)}$ \\
3D diffusion (Jander) (D3J) & $\frac{3(1-\alpha)^{2 / 3}}{2\left(1-(1-\alpha)^{1 / 3}\right.}$ \\
3D diffusion (Ginstling-Brounshtein) (D3GB) & $\frac{3}{2}\left((1-\alpha)^{\frac{1}{3}}-1\right)$ \\
\hline
\end{tabular}

order are obtained simultaneously), however, it only considers degradation reaction mechanism. The FC method considers the rate equation (eq. 3) where $f(\alpha)$ mechanism is the one expressed in eq. 4 . If the equation is considered for two different moments at two different temperatures, applying logarithms at both sides, and subtracting one to the other, the following equation is obtained:

$\Delta \ln \left(\frac{d \alpha}{d T}\right)=n \Delta \ln (1-\alpha)-\frac{E a}{R} \Delta T^{-1}$

And dividing by $\Delta \ln (1-\alpha)$ and rearranging terms, the Eq. (10) becomes:

$\frac{\Delta \ln \left(\frac{d \alpha}{d T}\right)}{\Delta \ln (1-\alpha)}=n-E a \frac{\Delta T^{-1}}{R \Delta \ln (1-\alpha)}$

Which is indeed a regression line, where the slope represents the activation energy $E a$ and the $y$-intercept is the reaction order. Preexponential factor $A$ can be obtained from eq. 10 after defining $E a$ and $n$.

\subsection{Fraser-Suzuki deconvolution}

During TGA the decomposition can be divided into parallel reactions that correspond to the decomposition of pseudo-components. For lignocellulosic biomass, the number of pseudo-components is three that correspond to hemicellulose, cellulose and lignin [45]. In order to obtain the TG curves of each pseudo-component, a deconvolution process is applied to DTG (first derivative of TG curve) signal. Among the possible deconvolution functions, Fraser-Suzuki deconvolution has been selected as it provides more accurate values [46,47]. The Fraser-Suzuki procedure for the $i$-th pseudo-component can be written as:

$\left(\frac{d \alpha}{d T}\right)_{i}=h_{i} \exp \left[-\frac{\ln 2}{s_{i}^{2}} \ln \left(1+2 s_{i} \frac{T-p_{i}}{w_{i}}\right)^{2}\right]$

Where $h$ denotes height, $s$ represents skewness or asymmetry, $w$ is the width of the curve and $p$ represents the position (which will correspond to the peak temperature). Th fitting accuracy will be defined by the coefficient of determination $R^{2}$ value and the F-test. Fig. 2 shows an example of Fraser-Suzuki deconvolution for three pseudo-components, named PS1, PS2 and PS3.

\section{Results \& discussion}

\subsection{Proximate analysis and torrefaction}

As it can be seen in Fig. 1, torrefied samples present a darker colour than feedstock: the higher torrefaction temperature, the darker the sample. Between both torrefaction temperatures, the most significant change can be seen after $250{ }^{\circ} \mathrm{C}$ torrefaction, compared to feedstock; nevertheless, there is a change of colour after $300^{\circ} \mathrm{C}$ torrefaction even if the difference between torrefied samples is not so prominent. This change of colour is due to the loss of surface and bound moisture and the release of light volatiles [9].

Indeed, the moisture content significantly decreases after torrefaction in every sample as can be seen in Table 2. Volatile content increases after torrefaction, which means that the thermal treatment modifies the structure of the samples breaking bonds and increasing volatile release in a substantial proportion for torrefaction at $250{ }^{\circ} \mathrm{C}$ but not that much after $300{ }^{\circ} \mathrm{C}$ torrefaction. As volatile content increases, fixed carbon decreases, even to $19 \%$. Nevertheless, fixed carbon content remains high enough to contribute to char formation. Ash contents present the higher values for PKS samples, followed by PMF samples in which the ash content slightly increases after torrefaction. 


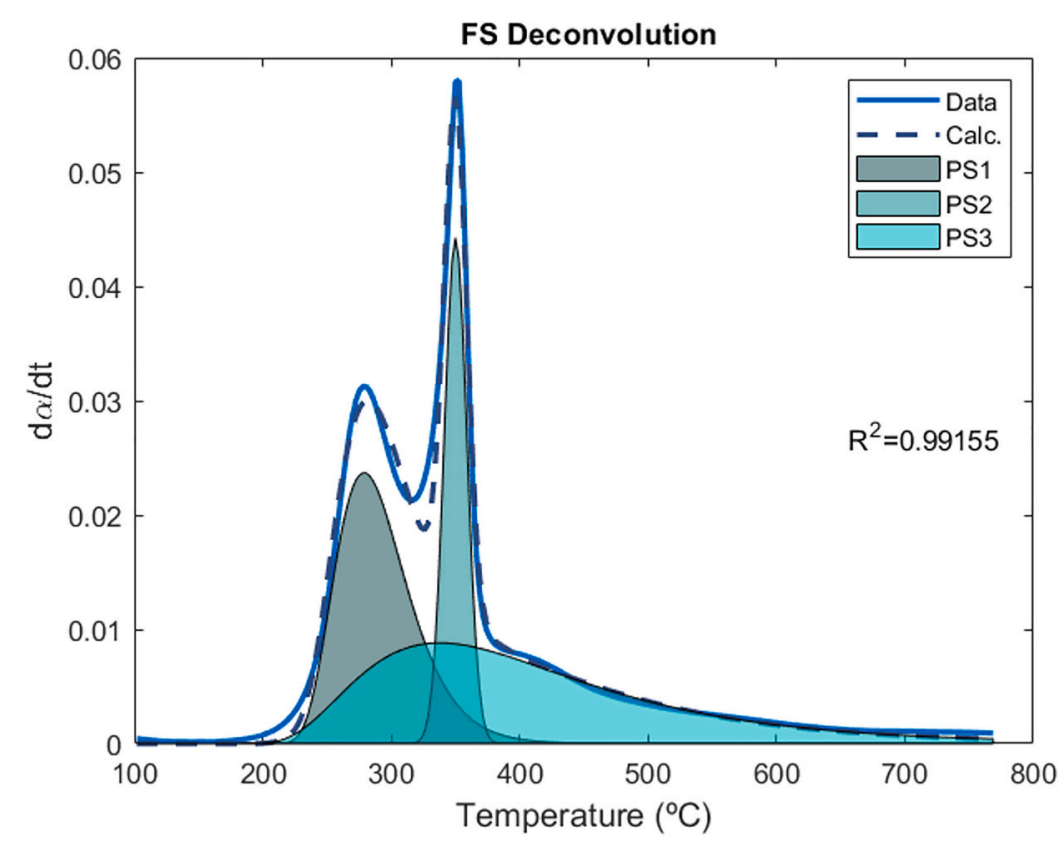

Fig. 2. Three component Fraser-Suzuki deconvolution.

Table 2

\begin{tabular}{lllll}
\multicolumn{5}{l}{ Proximate analysis. } \\
\hline \multicolumn{2}{l}{ Proximate analysis } & & & \\
\hline Sample & $\begin{array}{l}\text { Moisture } \\
(\%)\end{array}$ & $\begin{array}{l}\text { Ash (\%) d. } \\
\text { b. }\end{array}$ & $\begin{array}{l}\text { Volatile (\%) d. } \\
\text { b. }\end{array}$ & $\begin{array}{l}\text { Fixed Carbon (\%) d. } \\
\text { b. }\end{array}$ \\
\hline EFB & $6.46 \%$ & $2.88 \%$ & $72.71 \%$ & $24.40 \%$ \\
EFB T1 & $2.52 \%$ & $1.98 \%$ & $77.91 \%$ & $20.12 \%$ \\
EFB T2 & $1.84 \%$ & $2.42 \%$ & $78.58 \%$ & $19.00 \%$ \\
PKS & $7.01 \%$ & $9.54 \%$ & $66.81 \%$ & $23.65 \%$ \\
PKS T1 & $0.47 \%$ & $5.44 \%$ & $72.08 \%$ & $22.48 \%$ \\
PKS T2 & $0.87 \%$ & $4.41 \%$ & $73.02 \%$ & $22.57 \%$ \\
PMF & $8.79 \%$ & $5.75 \%$ & $62.73 \%$ & $31.52 \%$ \\
PMF T1 & $1.40 \%$ & $6.28 \%$ & $73.75 \%$ & $19.97 \%$ \\
PMF T2 & $1.12 \%$ & $6.59 \%$ & $72.61 \%$ & $20.80 \%$ \\
\hline
\end{tabular}

\subsection{Thermal analysis}

Fig. 3 shows the results for TGA and DTG of each sample. The first mass loss corresponds to moisture evaporation. The process is followed by devolatilization and char oxidation. The first peak in the DTG corresponds to the release of light volatiles, mainly hemicellulose; and the second one to the heavy volatile release (cellulose and lignin at the end). The EFB samples do not show those peaks, probably because of low hemicellulose content whose decomposition takes place at the same time as cellulose.

After $300{ }^{\circ} \mathrm{C}$ torrefaction, hemicellulose content should decrease, and a release of volatiles should take place, which means that the first peak is smaller than the second one or even disappears (as it happens in EFB samples).

The onset temperatures obtained for empty fruit bunches EFB samples are $236.8{ }^{\circ} \mathrm{C}, 239.7^{\circ} \mathrm{C}$ and $246.3^{\circ} \mathrm{C}$ for feedstock, T1 torrefaction and $\mathrm{T} 2$ torrefaction, respectively. It can be noticed that torrefaction slightly increases onset temperature as the light volatiles are released and the reaction requires more energy. Onset temperature increase also takes place in kernel shell PKS samples that increases from $218.4^{\circ} \mathrm{C}$ for feedstock, to $250.0^{\circ} \mathrm{C}$ for $\mathrm{T} 1$ torrefaction and $251{ }^{\circ} \mathrm{C}$ for $\mathrm{T} 2$ torrefaction; and mesocarp fibre PMF samples whose values for feedstock, T1 and T2 torrefaction are $222.7^{\circ} \mathrm{C}, 244.2^{\circ} \mathrm{C}$ and $241.2^{\circ} \mathrm{C}$ respectively.

\subsection{Biomass composition}

Palm oil wastes composition in terms of hemicellulose, cellulose and lignin vary between studies [48-50], and because of that, the results obtained in the present work have been compared to literature data and proved to fit in the ranges defined by previous works. Table 3 shows the results of each pseudo-component obtained from Fraser-Suzuki deconvolution, the remaining percentage corresponds to extractives and ashes. Palm kernel shell samples present higher content of lignin and lower cellulose contents than EFB and PMF samples.

According to Sukiran and co-workers [5] the thermal degradation of hemicellulose takes place between $200{ }^{\circ} \mathrm{C}$ and $320{ }^{\circ} \mathrm{C}$ due to its amorphous structure, which means that torrefied samples will present lower contents of hemicellulose than feedstock. However, it can be noticed that some samples present higher hemicellulose content after torrefaction than raw material. As torrefaction not only volatilizes part of the hemicellulose but modifies the chemical bonds from the other components, it is possible that the hemicellulose content reported includes part of those components with weaker bonds besides hemicellulose. After hemicellulose, cellulose is decomposed between $300{ }^{\circ} \mathrm{C}$ and $360{ }^{\circ} \mathrm{C}$, while lignin presents a higher temperature range of decomposition (from $200{ }^{\circ} \mathrm{C}$ to $800{ }^{\circ} \mathrm{C}$ ) due to the aromatic rings of its structure.

\subsection{Kinetic results}

As has been shown, torrefaction modifies the biomass composition in terms of cellulose, hemicellulose, and lignin; thus, the kinetic parameters of combustion will be modified too. The results from the kinetic parameters (activation energy, preexponential factor and order reaction) and the coefficient of determination $\left(R^{2}\right)$ are shown in Table 4, but also the results of two-sample F-test including the value of the test statistic (F-test), hypothesis tested $(h), p$-value and confidence interval ( $c i_{1}$, $c i_{2}$ ). Those results correspond to the best fitting (highest $R^{2}$ ) for both methods (Coats-Redfern and Freeman-Carroll).

According to the obtained $R^{2}$ and $p$-values, the samples present good fitting results for both methods however, Coats Redfern results have better determination coefficient in all samples but one: EFB T1 where the best fitting was obtained for Freeman-Carroll with a reaction order of 4.23. Indeed, EFB samples present a different thermal behaviour (Fig. 3) than the other samples, which may explain that in two of the three 

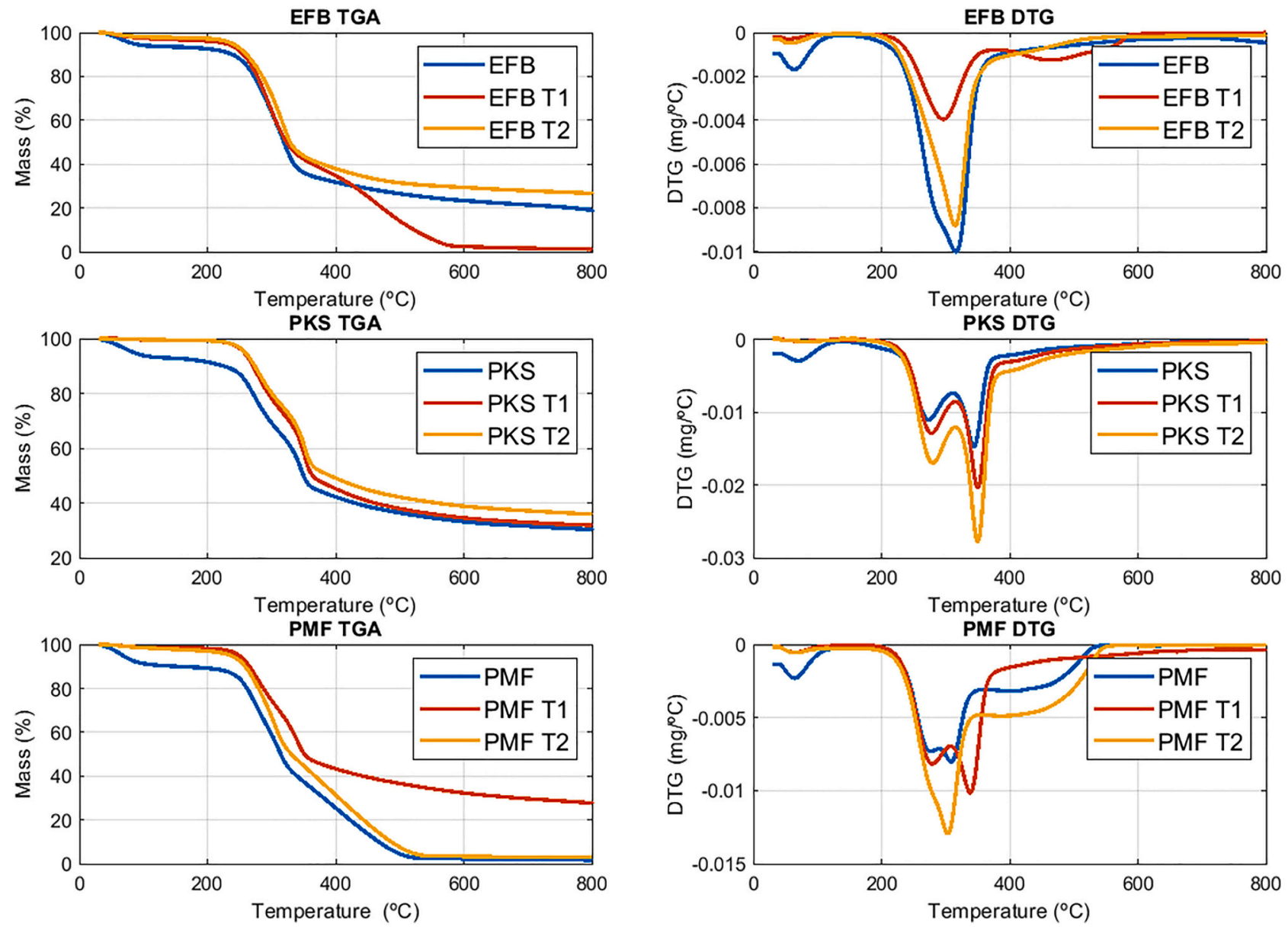

Fig. 3. TGA and DTG plots.

Table 3

Fraser Suzuki Deconvolution.

\begin{tabular}{lllll}
\hline \multicolumn{5}{l}{ Fraser Suzuki deconvolution } \\
\hline Sample & Hemicellulose (\%) & Cellulose (\%) & Lignin (\%) & $\mathrm{R}^{2}$ \\
\hline EFB & 20.53 & 38.70 & 18.16 & 0.99679 \\
EFB T1 & 14.49 & 31.20 & 19.86 & 0.99752 \\
EFB T2 & 12.46 & 35.22 & 19.49 & 0.99870 \\
PKS & 26.45 & 30.96 & 33.06 & 0.99354 \\
PKS T1 & 26.72 & 26.94 & 40.91 & 0.98885 \\
PKS T2 & 22.78 & 28.36 & 44.45 & 0.99155 \\
PMF & 32.09 & 39.44 & 17.15 & 0.99655 \\
PMF T1 & 29.22 & 31.12 & 12.35 & 0.99680 \\
PMF T2 & 32.91 & 44.07 & 12.05 & 0.98612 \\
\hline
\end{tabular}

samples, the reaction model is a diffusion instead of degradation.
Besides that, it can be noticed that activation energy increases after low temperature torrefaction as the thermal resistance is increased [51,52]. However, Ea slightly decreases for high temperature torrefaction (in all samples but EFB T2) as it was already pointed out by other authors [15]. Fig. 4 compares the obtained results for activation energy where the differences between CR and FC methods can be seen. Most of the samples present a slight difference comparing both methods, however, EFB shows the greatest differences due to the diffusion-controlled model.

If the preexponential factors are considered, it can be noticed that EFB T1 presents an unusual value. This can be explained due to fact that Freeman Carroll method makes assumptions that may introduce an error when calculating other kinetic parameters than activation energy [53]. Besides that, preexponential factor does not seem to be affected by the torrefaction process.

Some studies [54] concluded that palm shell and mesocarp fibre

Table 4

Kinetic parameters.

\begin{tabular}{|c|c|c|c|c|c|c|c|c|c|}
\hline \multicolumn{10}{|c|}{ Kinetic parameters } \\
\hline Sample & $\mathrm{n}$ & $\mathrm{Ea}(\mathrm{kJ} / \mathrm{mol})$ & $\mathrm{A}(1 / \mathrm{min})$ & $\mathrm{R}^{2}$ & F-test & $\mathrm{h}$ & p-value & $\mathrm{ci}_{1}$ & $\mathrm{ci}_{2}$ \\
\hline EFB & D3J & 109.52 & $9.90 \mathrm{E}+10$ & 0.99702 & 1.0030 & 0 & 0.99271 & 0.52595 & 1.91270 \\
\hline EFB T1 & $4.23 \mathrm{FC}$ & 124.55 & $1.32 \mathrm{E}+19$ & 0.99833 & 1.0017 & 0 & 0.99698 & 0.41588 & 2.41262 \\
\hline EFB T2 & D3J & 138.00 & $4.23 \mathrm{E}+13$ & 0.99990 & 1.0001 & 0 & 0.99979 & 0.46281 & 2.16116 \\
\hline PKS & 6.5 & 114.05 & $3.74 \mathrm{E}+13$ & 0.99894 & 1.0011 & 0 & 0.99783 & 0.46325 & 2.16323 \\
\hline PKS T1 & 7 & 122.26 & $8.24 \mathrm{E}+13$ & 0.99807 & 1.0019 & 0 & 0.99660 & 0.40655 & 2.46925 \\
\hline PKS T2 & 6 & 114.05 & $9.13 \mathrm{E}+12$ & 0.99452 & 1.0055 & 0 & 0.98893 & 0.45824 & 2.20639 \\
\hline PMF & 4 & 84.69 & $1.76 \mathrm{E}+10$ & 0.99582 & 1.0042 & 0 & 0.98949 & 0.53552 & 1.88308 \\
\hline PMF T1 & 3 & 91.78 & $4.08 \mathrm{E}+10$ & 0.99462 & 1.0054 & 0 & 0.98518 & 0.56713 & 1.78240 \\
\hline PMF T2 & 3 & 90.20 & $2.75 \mathrm{E}+10$ & 0.99941 & 1.0006 & 0 & 0.99875 & 0.47624 & 2.10223 \\
\hline
\end{tabular}




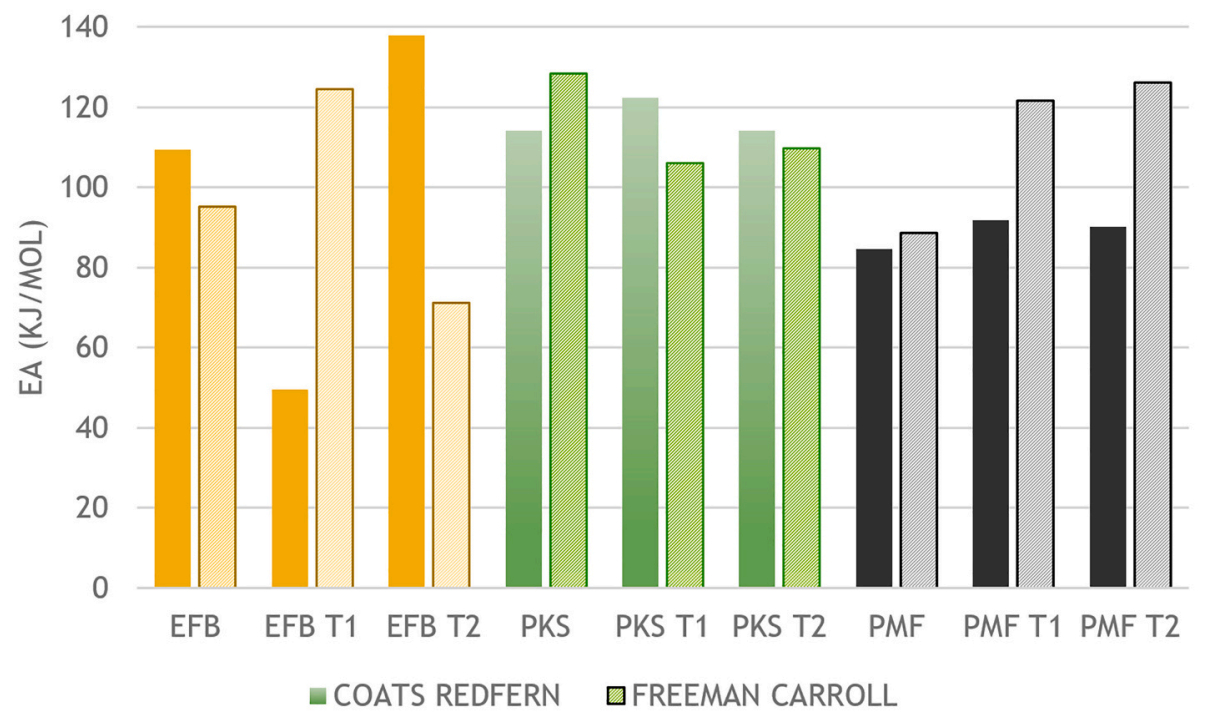

Fig. 4. Coats-Redfern and Freeman-Carroll Activation Energy values.

present lower activation energies as they have lower lignin content that starts decomposing at lower rates. However, Poudel and co-workers [11] obtained higher activation energies for EFB than PKS. This difference could be explained by the kinetic approach used in different studies. In the present work, the obtained values for the activation energy for PMF samples show the lowest activation energy (84-90 kJ/mol) followed EFB samples (109-138 kJ/mol) and PKS (114-122 kJ/mol). PMF lower activation energies could be explained by the lignin content, as it is the more thermally stable component. However, for EFB and PKS samples, lignin content is not as relevant as the reaction mechanisms. As shown in Fig. 3, EFB samples do not show a second peak in DTG curve, which means that there are not two differentiated volatilization stages. It can explain the higher activation energies required to release those volatiles, as heavy and light volatiles are more mixed up together than PKS, where two different stages are properly differentiated.

As it was mentioned when the TGA results were discussed, samples PKS and PMF present a different thermal behaviour than EFB, which produces an inflection point in the conversion function as shown in Fig. 5, where the curvature changes. Thus, a deeper kinetic analysis was performed in these samples using the CR method, considering two different step reactions: before and after inflection point. As it can be seen in Table 5, degradation is followed by a diffusion reaction during combustion, being the degradation reaction the main mechanism according to the previous results.

According to Barzegar and co-workers [38], Ea increases due to hemicellulose degradation and decrease for lignin decomposition, which explains the lower $E a$ values in the second step reaction. As it seems that more than one reaction mechanism takes place during the process, further studies should consider using DAEM or multicomponent models in order to properly define the reactions that occur.

\section{Conclusions}

Torrefaction pre-treatment significantly enhances palm oil wastes properties to be used as biomass, modifying the composition, and increasing thermal stability which leads to higher activation energies. Torrefaction reduces hemicellulose content, as its decomposition takes place in the first place (between $200^{\circ} \mathrm{C}$ and $320^{\circ} \mathrm{C}$ ) which also produces an increase on the onset temperature. EFB samples presented lower hemicellulose content than PKS and PMF samples, causing a different
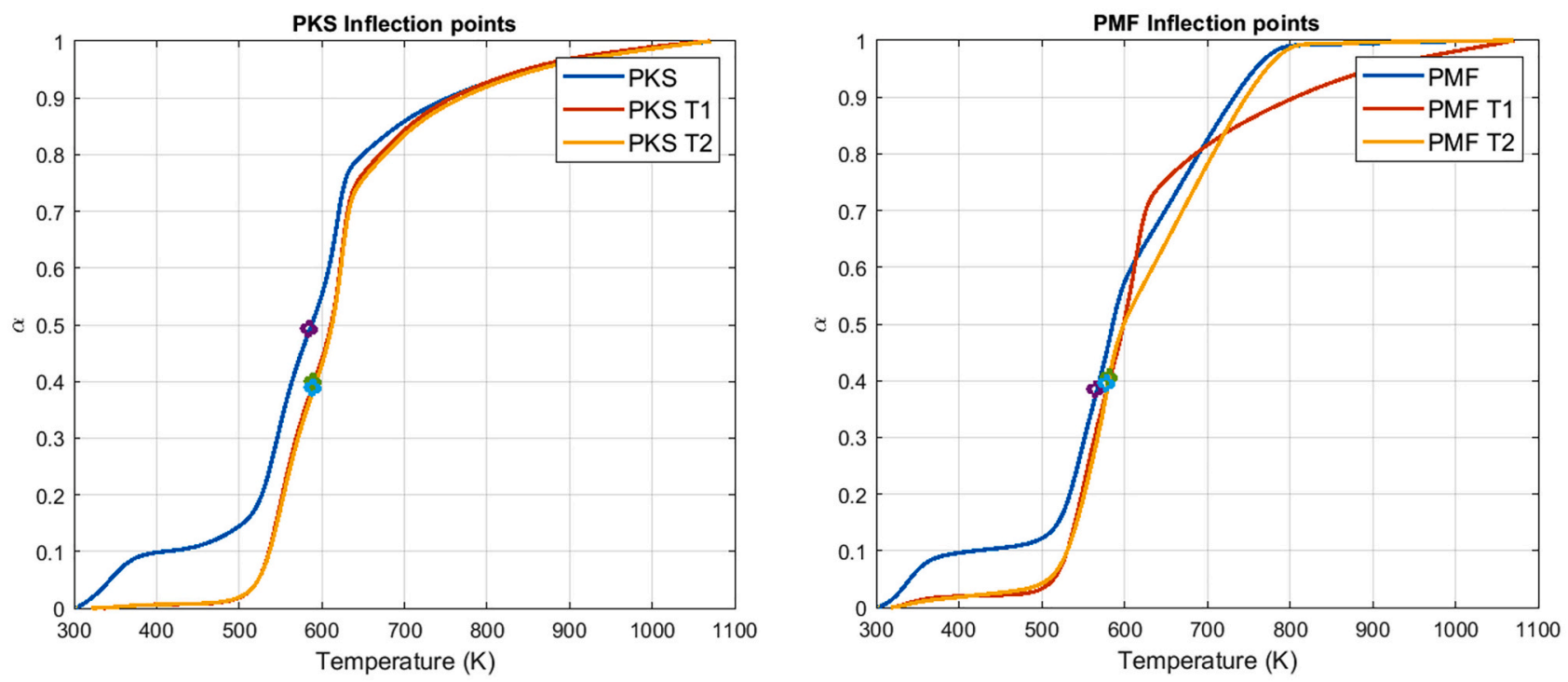

Fig. 5. TGA inflection points for PKS and PMF samples. 
Table 5

Step reactions kinetic parameters.

\begin{tabular}{|c|c|c|c|c|c|c|c|c|c|}
\hline Sample & $\mathrm{n}$ & $\mathrm{Ea}(\mathrm{kJ} / \mathrm{mol})$ & $\mathrm{A}(1 / \mathrm{min})$ & $\mathrm{R}^{2}$ & F-test & $\mathrm{h}$ & p-value & $\mathrm{ci}_{1}$ & $\mathrm{ci}_{2}$ \\
\hline \multicolumn{10}{|c|}{ First step reaction } \\
\hline PKS & 3.5 & 68.12 & $3.67 \mathrm{E}+08$ & 0.99531 & 1.0047 & 0 & 0.99071 & 0.45048 & 2.24082 \\
\hline PKS T1 & 7 & 123.88 & $1.19 \mathrm{E}+14$ & 0.99694 & 1.0031 & 0 & 0.99568 & 0.32201 & 3.12460 \\
\hline PKS T2 & 7 & 140.04 & $3.85 \mathrm{E}+15$ & 0.99645 & 1.0036 & 0 & 0.99326 & 0.43414 & 2.31988 \\
\hline PMF & 2 & 59.92 & $3.20 \mathrm{E}+07$ & 0.99889 & 1.0011 & 0 & 0.99831 & 0.34978 & 2.86528 \\
\hline PMF T1 & 6.5 & 137.33 & $2.82 \mathrm{E}+15$ & 0.99932 & 1.0007 & 0 & 0.99871 & 0.43289 & 2.31322 \\
\hline PMF T2 & 2 & 79.67 & $2.03 \mathrm{E}+09$ & 0.99904 & 1.0010 & 0 & 0.99813 & 0.44109 & 2.27147 \\
\hline \multicolumn{10}{|c|}{ Second step reaction } \\
\hline PKS & D2 & 66.66 & $1.88 \mathrm{E}+07$ & 0.98150 & 1.0188 & 0 & 0.97366 & 0.32707 & 3.17374 \\
\hline PKS T1 & D2 & 90.49 & $1.95 \mathrm{E}+09$ & 0.97414 & 1.0265 & 0 & 0.96160 & 0.34464 & 3.05765 \\
\hline PKS T2 & D2 & 93.24 & $3.36 \mathrm{E}+09$ & 0.98023 & 1.0202 & 0 & 0.96966 & 0.35644 & 2.91982 \\
\hline PMF & D3J & 34.73 & $3.91 \mathrm{E}+03$ & 0.97649 & 1.0241 & 0 & 0.92159 & 0.63633 & 1.64808 \\
\hline PMF T1 & D2 & 81.42 & $3.87 \mathrm{E}+08$ & 0.99797 & 1.0020 & 0 & 0.99702 & 0.33641 & 2.98466 \\
\hline PMF T2 & D3J & 37.00 & $5.03 \mathrm{E}+03$ & 0.99501 & 1.0050 & 0 & 0.98348 & 0.62449 & 1.61741 \\
\hline
\end{tabular}

thermal behaviour during TGA.

This study provides information regarding the influence of palm oil wastes torrefaction not only on its composition but also on the kinetic reactions for energy conversion. A deep understanding of torrefaction process in terms of composition and combustion, helps increase palm oil wastes energetic efficiency by defining the best requirements for its use. Even if these compositions must be treated as estimations, the method proved to be accurate considering $R^{2}$ values and the literature data. This can be explained by the skewness parameter integrated in the FraserSuzuki deconvolution, as it considers the possible asymmetry presented in the deconvoluted curves, which provides better fitting than classic methods such as Gaussian deconvolution. However, further research could focus on determining the accuracy of the Fraser-Suzuki estimations.

Regarding the kinetic methods used, the results show that CoatsRedfern method gives better fitting than Freeman-Carroll. However, both methods are non-isothermal model-fitting methods, so further studies should focus on model-free methods in order to compare them. More precisely DAEM method could provide very interesting results as it has been noticed that more than one reaction takes place during the process, which means that the process is found to be complex.

Although this fact, the results showed that each sample type behaves in a particular way: while EFB samples showed better fitting to diffusion reaction, PKS and PMF samples results appear to be n-order reactions, specifically, PKS showed higher order reactions (between 6 and 7) than PMF (between 3 and 4). This means that the present study provides a preliminary view of the reaction mechanisms.

\section{Aknowledgement}

This research did not receive any specific grant from funding agencies in the public, commercial, or not-for-profit sectors.

\section{Declaration of Competing Interest}

The authors declare that they have no known competing financial interests or personal relationships that could have appeared to influence the work reported in this paper.

\section{References}

[1] Eurostat - Data Explorer. https://appsso.eurostat.ec.europa.eu/nui/submitVie wTableAction.do, 2021. (Accessed 10 June 2020).

[2] A. Demirbas, The social, economic, and environmental importance of biofuels in the future, Energy Sour. B Econ. Planning, Policy 12 (2017) 47-55, https://doi. org/10.1080/15567249.2014.966926.

[3] L. Gustavsson, P. Svenningsson, Substituting fossil fuels with biomass, Energy Convers. Manag. 37 (1996) 1211-1216.

[4] S.V. Vassilev, C.G. Vassileva, V.S. Vassilev, Advantages and disadvantages of composition and properties of biomass in comparison with coal: an overview, Fuel. 158 (2015) 330-350, https://doi.org/10.1016/j.fuel.2015.05.050.
[5] M.A. Sukiran, F. Abnisa, W.M.A. Wan Daud, N. Abu Bakar, S.K. Loh, A review of torrefaction of oil palm solid wastes for biofuel production, Energy Convers. Manag. 149 (2017) 101-120, https://doi.org/10.1016/j.enconman.2017.07.011.

[6] E. Hambali, M. Rivai, The Potential of Palm Oil Waste Biomass in Indonesia in 2020 and 2030, IOP Conf. Ser. Earth Environ. Sci. 65 (2017), https://doi.org/ 10.1088/1755-1315/65/1/012050.

[7] Y. Uemura, W.N. Omar, T. Tsutsui, S.B. Yusup, Torrefaction of oil palm wastes, Fuel. 90 (2011) 2585-2591, https://doi.org/10.1016/j.fuel.2011.03.021.

[8] S.K. Loh, The potential of the Malaysian oil palm biomass as a renewable energy source, Energy Convers. Manag. 141 (2017) 285-298, https://doi.org/10.1016/j. enconman.2016.08.081.

[9] D. Nhuchhen, P. Basu, B. Acharya, A Comprehensive Review on Biomass Torrefaction, Int. J. Renew. Energy Biofuels 2014 (2014) 1-56, https://doi.org/ 10.5171/2014.506376.

[10] Y. Uemura, V. Sellappah, T.H. Trinh, S. Hassan, K. Ichiro Tanoue, Torrefaction of empty fruit bunches under biomass combustion gas atmosphere, Bioresour. Technol. 243 (2017), https://doi.org/10.1016/j.biortech.2017.06.057.

[11] J. Poudel, T.I. Ohm, J.H. Gu, M.C. Shin, S.C. Oh, Comparative study of torrefaction of empty fruit bunches and palm kernel shell, J. Mater. Cycles Waste Manag. 19 (2017) 917-927, https://doi.org/10.1007/s10163-016-0492-1.

[12] N. Yaacob, N.A. Rahman, S. Matali, S.S. Idris, A.B. Alias, An overview of oil palm biomass torrefaction: Effects of temperature and residence time, IOP Conf. Ser. Earth Environ. Sci. 36 (2016), https://doi.org/10.1088/1755-1315/36/1/012038.

[13] F.R.A. Abdul Wahid, S. Saleh, N.A.F. Abdul Samad, Estimation of higher heating Value of Torrefied Palm Oil Wastes from Proximate Analysis, Energy Procedia 138 (2017) 307-312, https://doi.org/10.1016/j.egypro.2017.10.102.

[14] M.J.C. Van der Stelt, H. Gerhauser, J.H.A. Kiel, K.J. Ptasinski, Biomass upgrading by torrefaction for the production of biofuels: a review, Biomass Bioenergy 35 (2011) 3748-3762, https://doi.org/10.1016/j.biombioe.2011.06.023.

[15] S. Wang, G. Dai, B. Ru, Y. Zhao, X. Wang, G. Xiao, Z. Luo, Influence of torrefaction on the characteristics and pyrolysis behavior of cellulose, Energy. 120 (2017) 864-871, https://doi.org/10.1016/j.energy.2016.11.135.

[16] M. Valix, S. Katyal, W.H. Cheung, Combustion of thermochemically torrefied sugar cane bagasse, Bioresour. Technol. 223 (2017) 202-209, https://doi.org/10.1016/j. biortech.2016.10.053.

[17] Z. Chen, M. Hu, X. Zhu, D. Guo, S. Liu, Z. Hu, B. Xiao, J. Wang, M. Laghari, Characteristics and kinetic study on pyrolysis of five lignocellulosic biomass via thermogravimetric analysis, Bioresour. Technol. 192 (2015) 441-450, https://doi. org/10.1016/j.biortech.2015.05.062.

[18] A. Álvarez, C. Pizarro, R. García, J.L. Bueno, A.G. Lavín, Determination of kinetic parameters for biomass combustion, Bioresour. Technol. 216 (2016) 36-43, https://doi.org/10.1016/j.biortech.2016.05.039.

[19] A. Saddawi, J.M. Jones, A. Williams, M.A. Wójtowicz, Kinetics of the thermal decomposition of biomass, Energy Fuel 24 (2010) 1274-1282, https://doi.org/ 10.1021/ef900933k.

[20] C.E. Greenhalf, D.J. Nowakowski, A.V. Bridgwater, J. Titiloye, N.E. Yates, A. Riche, I. Shield, Thermochemical characterisation of straws and high yielding perennial grasses, Ind. Crop. Prod. 36 (2012) 449-459, https://doi.org/10.1016/j. indcrop.2011.10.025.

[21] M.R.B. Guerrero, M. Marques Da Silva Paula, M.M. Zaragoza, J.S. Gutiérrez, V. G. Velderrain, A.L. Ortiz, V. Collins-Martínez, Thermogravimetric study on the pyrolysis kinetics of apple pomace as waste biomass, Int. J. Hydrog. Energy 39 (2014) 16619-16627, https://doi.org/10.1016/j.ijhydene.2014.06.012.

[22] S. Subramanian, U.B. Reddy Ragula, Pyrolysis kinetics of Hibiscus rosa sinensis and Nerium oleander, Biofuels 7269 (2018) 1-15, https://doi.org/10.1080/ 17597269.2018.1432274.

[23] B. Janković, M.B. Radojević, M. Balac, D.D. Stojiljković, N.G. Manić, Thermogravimetric study on the pyrolysis kinetic mechanism of waste biomass from fruit processing industry, Therm. Sci. 24 (2020) 4221-4239, https://doi.org/ 10.2298/TSCI200213191J.

[24] A.W. Coats, J.P. Redfern, Kinetic Parameters from Thermogravimetric Data, Nature. 201 (1964) 68-69, https://doi.org/10.1038/201068a0.

[25] E.S. Freeman, B. Carroll, The application of thermoanalytical techniques to reaction kinetics. The thermogravimetric evaluation of the kinetics of the 
decomposition of calcium oxalate monohydrate, J. Phys. Chem. 62 (1958) 394-397, https://doi.org/10.1021/j150562a003.

[26] D. Trache, A. Abdelaziz, B. Siouani, A simple and linear isoconversional method to determine the pre-exponential factors and the mathematical reaction mechanism functions, J. Therm. Anal. Calorim. 128 (2017) 335-348, https://doi.org/10.1007/ s10973-016-5962-0.

[27] H.L. Friedman, Kinetics of thermal degradation of char-forming plastics from thermogravimetry. Application to a phenolic plastic, J. Polym. Sci. Part C Polym. Symp. 6 (1964) 183-195, https://doi.org/10.1002/polc.5070060121.

[28] H.E. Kissinger, Reaction Kinetics in Differential thermal Analysis, Anal. Chem. 29 (1957) 1702-1706, https://doi.org/10.1021/ac60131a045.

[29] T. Akahira, T. Sunose, Method of determining activation deterioration constant of electrical insulating materials, Res Rep Chiba Inst Technol (Sci Technol). 16 (1971) 22-31.

[30] J.H. Flynn, L.A. Wall, A quick, direct method for the determination of activation energy from thermogravimetric data, J. Polym. Sci. Part B Polym. Lett. 4 (1966) 323-328, https://doi.org/10.1002/pol.1966.110040504.

[31] T. Ozawa, A new method of analyzing thermogravimetric data, Bull. Chem. Soc. Jpn. 38 (1965) 1881-1886, https://doi.org/10.1246/bcsj.38.1881.

[32] J.W. Cumming, Reactivity assessment of coals via a weighted mean activation energy, Fuel. 63 (1984) 1436-1440, https://doi.org/10.1016/0016-2361(84) 90353-3.

[33] A.K. Burnham, Global kinetic analysis of complex materials, Energy Fuel 13 (1999) 1-22, https://doi.org/10.1021/ef9800765.

[34] N.H.H.M. Harun, N.A.F.A. Samad, S. Saleh, Development of Kinetics Model for Torrefaction of empty Fruit Bunch from Palm Oil Waste, Energy Procedia 105 (2017) 744-749, https://doi.org/10.1016/j.egypro.2017.03.385.

[35] H. Duan, Z. Zhang, M.M. Rahman, X. Guo, X. Zhang, J. Cai, Insight into torrefaction of woody biomass: Kinetic modeling using pattern search method, Energy. 201 (2020) 117648, https://doi.org/10.1016/j.energy.2020.117648.

[36] S. Szufa, G. Wielgosiński, P. Piersa, J. Czerwińska, M. Dzikuć, Ł. Adrian, W. Lewandowska, M. Marczak, Torrefaction of straw from oats and maize for use as a fuel and additive to organic fertilizers-TGA analysis, kinetics as products for agricultural purposes, Energies 13 (2020), https://doi.org/10.3390/en13082064.

[37] L. Zhao, H. Zhou, Z. Xie, J. Li, Y. Yin, Effects of potassium on solid products of peanut shell torrefaction, Energy Sour. A Recover. Util. Environ. Eff. 42 (2020) 1235-1246, https://doi.org/10.1080/15567036.2019.1602232.

[38] R. Barzegar, A. Yozgatligil, H. Olgun, A.T. Atimtay, TGA and kinetic study of different torrefaction conditions of wood biomass under air and oxy-fuel combustion atmospheres, J. Energy Inst. 93 (2020) 889-898, https://doi.org/ 10.1016/j.joei.2019.08.001.

[39] A. Saddawi, J.M. Jones, A. Williams, C. Le Coeur, Commodity fuels from biomass through pretreatment and torrefaction: Effects of mineral content on torrefied fuel characteristics and quality, Energy Fuel 26 (2012) 6466-6474, https://doi.org/ 10.1021/ef2016649.

[40] M.H. Sulaiman, Y. Uemura, M.T. Azizan, Torrefaction of empty fruit bunches in inert condition at various temperature and time, Procedia Eng. 148 (2016) 573-579, https://doi.org/10.1016/j.proeng.2016.06.514.
[41] M.J. Prins, K.J. Ptasinski, F.J.J.G. Janssen, More efficient biomass gasification via torrefaction, Energy. 31 (2006) 3458-3470, https://doi.org/10.1016/j. energy.2006.03.008.

[42] J. Cai, W. Wu, R. Liu, G.W. Huber, A distributed activation energy model for the pyrolysis of lignocellulosic biomass, Green Chem. 15 (2013) 1331-1340, https:// doi.org/10.1039/c3gc36958g.

[43] A. Perejón, E.S. Pedro, J.M. Criado, A.P. Luis, Kinetic Analysis of Complex SolidState Reactions. A New Deconvolution Procedure, 2011, pp. 1780-1791.

[44] C. Sronsri, B. Boonchom, Thermal kinetic analysis of a complex process from a solid-state reaction by deconvolution procedure from a new calculation method and related thermodynamic functions of $\mathrm{Mn} 0.90 \mathrm{Co} 0.05 \mathrm{Mg} 0.05 \mathrm{HPO} 4.3 \mathrm{H} 2 \mathrm{O}$, Trans. Nonferrous Metals Soc. China 28 (2018) 1887-1902, https://doi.org/ 10.1016/S1003-6326(18)64834-4.

[45] Z. Li, W. Zhao, B. Meng, C. Liu, Q. Zhu, G. Zhao, Kinetic study of corn straw pyrolysis: Comparison of two different three-pseudocomponent models, Bioresour. Technol. 99 (2008) 7616-7622, https://doi.org/10.1016/j.biortech.2008.02.003.

[46] Z. Cheng, W. Wu, P. Ji, X. Zhou, R. Liu, J. Cai, Applicability of Fraser-Suzuki function in kinetic analysis of DAEM processes and lignocellulosic biomass pyrolysis processes, J. Therm. Anal. Calorim. 119 (2015) 1429-1438, https://doi. org/10.1007/s10973-014-4215-3.

[47] M. Hu, Z. Chen, S. Wang, D. Guo, C. Ma, Y. Zhou, J. Chen, M. Laghari, S. Fazal, B. Xiao, B. Zhang, S. Ma, Thermogravimetric kinetics of lignocellulosic biomass slow pyrolysis using distributed activation energy model, Fraser - Suzuki deconvolution, and iso-conversional method, Energy Convers. Manag. 118 (2016) 1-11, https://doi.org/10.1016/j.enconman.2016.03.058.

[48] D. Chen, A. Gao, K. Cen, J. Zhang, X. Cao, Z. Ma, Investigation of biomass torrefaction based on three major components: Hemicellulose, cellulose, and lignin, Energy Convers. Manag. 169 (2018) 228-237, https://doi.org/10.1016/j. enconman.2018.05.063.

[49] G. Dai, Q. Zou, S. Wang, Y. Zhao, L. Zhu, Q. Huang, Effect of torrefaction on the structure and pyrolysis behavior of lignin, Energy Fuel 32 (2018) 4160-4166, https://doi.org/10.1021/acs.energyfuels.7b03038.

[50] A. Zheng, L. Jiang, Z. Zhao, Z. Huang, K. Zhao, G. Wei, X. Wang, F. He, H. Li, Impact of torrefaction on the chemical structure and catalytic fast pyrolysis behavior of hemicellulose, lignin, and cellulose, Energy Fuel 29 (2015) 8027-8034, https://doi.org/10.1021/acs.energyfuels.5b01765.

[51] J. Meng, J. Park, D. Tilotta, S. Park, The effect of torrefaction on the chemistry of fast-pyrolysis bio-oil, Bioresour. Technol. 111 (2012) 439-446, https://doi.org/ 10.1016/j.biortech.2012.01.159.

[52] K.Q. Tran, Q.V. Bach, T.T. Trinh, G. Seisenbaeva, Non-isothermal pyrolysis of torrefied stump - a comparative kinetic evaluation, Appl. Energy 136 (2014) 759-766, https://doi.org/10.1016/j.apenergy.2014.08.026.

[53] J.M. Criado, D. Dollimore, G.R. Heal, A critical study of the suitability of the freeman and Carroll method for the kinetic analysis of reactions of thermal decomposition of solids, Thermochim. Acta 54 (1982) 159-165, https://doi.org/ 10.1016/0040-6031(82)85075-2.

[54] F. Surahmanto, H. Saptoadi, H. Sulistyo, T.A. Rohmat, Investigation of the slow pyrolysis kinetics of oil palm solid waste by the distributed activation energy model, Biofuels 0 (2017) 1-8, https://doi.org/10.1080/17597269.2017.1387750. 